\title{
Implications of the ACC/AHA risk score for prediction of heart failure: the Rotterdam Study
}

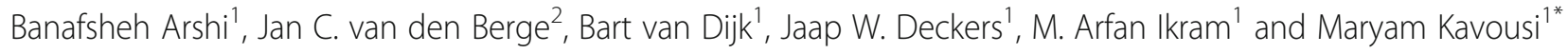

\begin{abstract}
Background: Despite the growing burden of heart failure (HF), there have been no recommendations for use of any of the primary prevention models in the existing guidelines. HF was also not included as an outcome in the American College of Cardiology/American Heart Association (ACC/AHA) risk score.

Methods: Among 2743 men and 3646 women aged $\geq 55$ years, free of HF, from the population-based Rotterdam Study cohort, 4 Cox models were fitted using the predictors of the ACC/AHA, ARIC and Health-ABC risk scores. Performance of the models for 10-year HF prediction was evaluated. Afterwards, performance and net reclassification improvement (NRI) for adding NT-proBNP to the ACC/AHA model were assessed.

Results: During a median follow-up of 13 years, 429 men and 489 women developed HF. The ARIC model had the highest performance [C-statistic (95\% confidence interval [CI]): $0.80(0.78 ; 0.83)$ and $0.80(0.78 ; 0.83)$ in men and women, respectively]. The c-statistic for the ACC/AHA model was $0.76(0.74 ; 0.78)$ in men and $0.77(0.75 ; 0.80)$ in women. Adding NT-proBNP to the ACC/AHA model increased the c-statistic to 0.80 (0.78 to 0.83 ) in men and 0.81 (0.79 to 0.84) in women. Sensitivity and specificity of the ACC/AHA model did not drastically change after addition of NT-proBNP. NRI $(95 \% \mathrm{Cl})$ was $-23.8 \%(-19.2 \%$; $-28.4 \%)$ in men and $-27.6 \%(-30.7 \%$; $-24.5 \%)$ in women for events and 57.9\% (54.8\%; 61.0\%) in men and 52.8\% (50.3\%; 55.5\%) in women for non-events.

Conclusions: Acceptable performance of the model based on risk factors included in the ACC/AHA model advocates use of this model for prediction of HF risk in primary prevention setting. Addition of NT-proBNP modestly improved the model performance but did not lead to relevant discrimination improvement in clinical risk reclassification.
\end{abstract}

Keywords: Heart failure, Prediction, Primary prevention, NT-proBNP

\footnotetext{
* Correspondence: m.kavousi@erasmusmc.nl

${ }^{1}$ Department of Epidemiology, Erasmus MC - University Medical Center

Rotterdam, Rotterdam, The Netherlands

Full list of author information is available at the end of the article
}

\section{$\triangle B M C$}

C C The Author(s). 2021 Open Access This article is licensed under a Creative Commons Attribution 4.0 International License, which permits use, sharing, adaptation, distribution and reproduction in any medium or format, as long as you give appropriate credit to the original author(s) and the source, provide a link to the Creative Commons licence, and indicate if changes were made. The images or other third party material in this article are included in the article's Creative Commons licence, unless indicated otherwise in a credit line to the material. If material is not included in the article's Creative Commons licence and your intended use is not permitted by statutory regulation or exceeds the permitted use, you will need to obtain permission directly from the copyright holder. To view a copy of this licence, visit http://creativecommons.org/licenses/by/4.0/. The Creative Commons Public Domain Dedication waiver (http://creativecommons.org/publicdomain/zero/1.0/) applies to the data made available in this article, unless otherwise stated in a credit line to the data. 


\section{Background}

Heart failure (HF) remains a major public health problem among men and women worldwide $[1,2]$. The growing morbidity and mortality of $\mathrm{HF}$, along with poor quality of life and prognosis, high costs, and the challenges of treating clinically overt HF highlight the need for more efficient preventive strategies [3, 4]. To identify high risk individuals who would benefit most from early prevention, several HF risk prediction models have been developed [5, 6]. However, none of these models have been recommended for routine use in clinical practice [5].

The recent American College of Cardiology (ACC)/ American Heart Association (AHA) guidelines use the pooled cohort equations (PCE) to predict 10-year risk of atherosclerotic cardiovascular disease (ASCVD). Compared to the previous guidelines, the newer guidelines have expanded the focus from coronary heart disease (CHD) only to an ASCVD outcome that additionally includes stroke [7]. Due to variability between studies in ascertainment of HF, incident HF has not been included in this newly expanded outcome. The PCE is comprised of the traditional cardiovascular risk factors which were among the ten most consistently reported predictors included in HF prediction models in a recent metaanalysis [6]. Compared to the more specific HF prediction models, risk factors included in the PCE are simple to measure and available in most clinical settings.

In this study, we assessed the performance of a model fitted based on the risk factors used in the PCE (ACC/ AHA model) for 10-year HF prediction among men and women from the large prospective population-based Rotterdam Study. We also compared the performance of this model for HF prediction with the performance of models based on risk factors included in the two risk scores that have been specifically developed and validated to predict HF in the general population; namely the Atherosclerosis Risk in Communities (ARIC) and the Health Aging and Body Composition (Health ABC) HF risk scores [8, 9]. Furthermore, we investigated whether addition of NT-proBNP, to the ACC/AHA risk score improved HF risk prediction.

\section{Methods}

\section{Study sample}

This project was carried out within the framework of the Rotterdam Study, a prospective population-based study among subjects 45 years and older in Rotterdam, the Netherlands. The baseline examination of the Rotterdam Study included 7983 individuals and was completed between 1989 and 1993 (RS-I). The cohort has been extended twice (3011 individuals, RS-II, recruited in 20002001 and 3932 individuals, RS-III, in 2006) to include participants who were 45 years or older or had moved to the study area. Rotterdam Study participants have been followed up ever since and the examinations have been repeated every 3-4years. The overall response for all three study cycles at entry was $72.0 \%(14,926$ of 20,744$)$. The rationale and design of the study have been previously described [10]. The Rotterdam Study has been approved by the Medical Ethics Committee of the Erasmus MC (registration number MEC 02.1015) and by the Dutch Ministry of Health, Welfare, and Sport (Population Screening Act WBO, license number 1071272159521-PG). The Rotterdam Study has been entered into the Netherlands National Trial Register (NTR; www. trialregister.nl) and into the WHO International Clinical Trials Registry Platform (ICTRP; www.who.int/ictrp/ network/primary/en/) under shared catalog number NTR6831. All participants provided written informed consent to participate in the study and to have their information obtained information from their treating physicians.

The present study used data from the third examination of the original cohort (RS-I-3, 1997-1999, $n=$ 4755) and the first examination of the extended cohort (RS-II-1, $n=3011$ ) had blood samples (RS-I-3, $n=4063$ and RS-II-1, $n=2630$ ). We excluded participants with a history of HF at baseline $(n=258)$, those with incomplete data at baseline or lost to follow-up $(n=46)$. After exclusions, 6389 participants (2743 men, 3646 women) were included in the study (Fig. 1).

\section{Predictors of HF}

Body mass index (BMI) was calculated based on weight in kilograms divided by height in meters squared. Blood pressure was measured on the right arm using a random-zero sphygmomanometer at sitting position. Two measurements were performed and the average of the two was used in the analyses. Antihypertensive treatment for hypertension, use of lipid lowering medication, history of diabetes mellitus, and history of CHD were based on clinical information obtained from general practitioners and letters or discharge reports from medical specialists [11]. Information on smoking behavior was acquired from questionnaires. For the ACC/AHA model, participants were classified as current smokers versus former or never smokers. For the Health $A B C$ and ARIC models, smoking status was classified as current, former, and never. Fasting serum glucose levels were determined using the glucose hexokinase method and serum total and high-density lipoprotein (HDL) cholesterol were measured using an automatic enzymatic procedure (Hitachi 911, Roche CHOD PAP). Serum creatinine levels were measured using an enzymatic assay (Roche Diagnostics, Mannheim, Germany) which was calibrated by isotope dilution mass spectrometry. Serum NT-proBNP was measured using a commercially available electrochemiluminescence immunoassay (Elecsys 


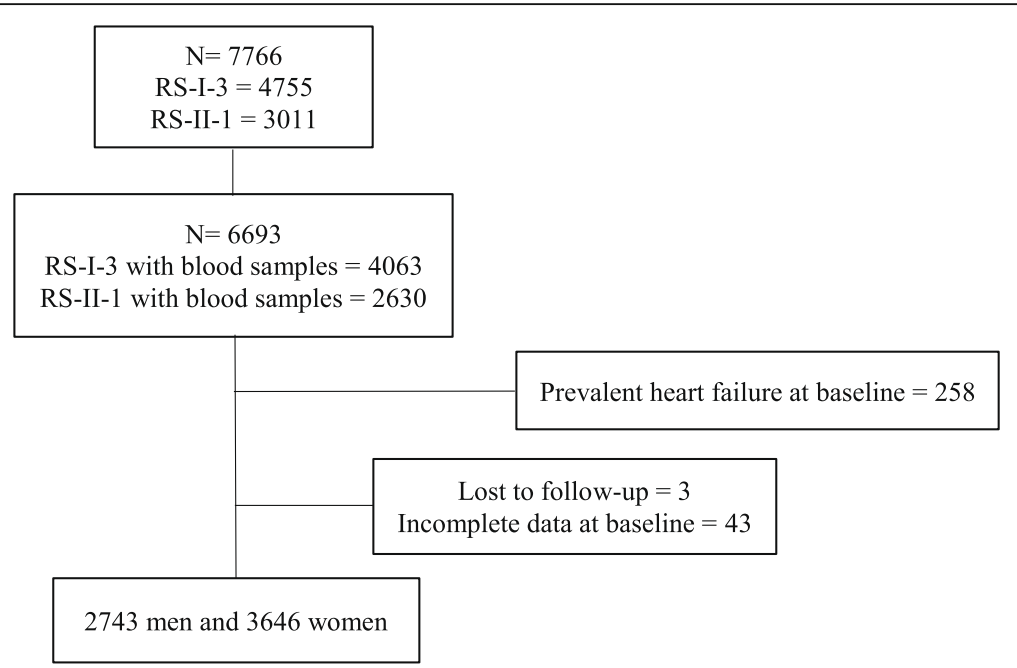

Fig. 1 Flowchart of the included study participants

proBNP, F Hoffman-La Roche Ltd.) on an Elecsys 2010 analyzer [12]. Left ventricular hypertrophy (LVH) was diagnosed based on Sokolov-Lyon criteria by the Modular ECG Analysis System program with an algorithm taking into account QRS voltages with an age-dependent correction and repolarization [13]. Presence of atrial fibrillation (AF) was based on the clinical and ECG evidence from medical records [11].

\section{HF assessment}

Ascertainment of HF for the Rotterdam Study has been previously described [11]. Information on prevalent HF cases at entry were obtained from a database containing hospital discharge diagnoses from all hospitals in Rotterdam at entry $[11,14]$. During follow-up, diagnosis of incident HF was also based on clinical information systematically collected from the general practitioner medical records and verified hospital discharge diagnoses collected from all hospitals in Rotterdam. Based on the criteria of the European Society of Cardiology (ESC), the diagnosis of definite HF was based on the presence of two signs or symptoms suggestive of HF, established by objective evidence of cardiac dysfunction, confirmed by a medical specialist [15]. HF was classified as probable if at least two typical symptoms of HF were present and at least one of the following: history of CVD (MI, valvular heart disease, hypertension), response to treatment for HF, or objective evidence of cardiac dysfunction, while symptoms could not be attributed to another disease. In accordance with the ESC guidelines, only definite and probable cases were used in the Rotterdam Study definition [15].

The incident date for HF was defined as the date of the first occurrence of symptoms suggestive of HF from the medical records or the day of receipt of a first prescription for a loop diuretic or an angiotensin-converting enzyme inhibitor, whichever one preceded [11].

\section{Statistical analysis}

Baseline characteristics of men and women were presented as mean [standard deviation (SD)] for normally distributed data and as median [interquartile range (IQR)] for skewed data and were compared using the Student $t$ tests for continuous variables and $\chi^{2}$ tests for categorical data. Logarithmic transformation was made on NT-proBNP to account for its skewed distribution. We used multiple imputation for missing values on covariates (All missing <5\%) [16]. Parameter estimates were obtained by pooling 5 imputed datasets using Rubin rules [16].

Three different Cox proportional hazards models were developed by refitting risk factors from the PCE risk score (ACC/AHA model), the ARIC HF risk score (ARIC model) and the Health $\mathrm{ABC}$ HF risk score (Health $\mathrm{ABC}$ model). Although these models were refitted, for simplicity, we call them ACC/AHA, ARIC, and Health ABC models. Ten-year HF risk was estimated per model. Predictors included in the ACC/AHA model were age, total and HDL cholesterol, systolic blood pressure, antihypertensive treatment, current smoking, and history of diabetes. The ARIC model included age, heart rate, systolic blood pressure, antihypertensive treatment, history of diabetes, history of CHD, smoking status (current, former, never), BMI and NT-proBNP. The Health $\mathrm{ABC}$ model included age, history of CHD, LVH, systolic blood pressure, heart rate, smoking status (current, former, never), glucose, and creatinine. Due to unavailability, albumin measurement was left out of the Health ABC model. In addition, a fourth model was built that additionally included NT-proBNP in the ACC/AHA 
model as a predictor (ACC/AHA + NT-proBNP model). All models were separately developed for men and women.

For each model, a full model including interaction terms between age and NT-proBNP and between SBP and antihypertensive medication use (if applicable) and natural splines with 2 knots for age and NT-proBNP (if applicable) was first specified, forcing on the variables of the respective risk scores. Schoenfeld's test of residuals using the Kaplan-Meier estimate of the survival function was used to check the proportionality of the regressions. Then, backward selection was performed using log likelihood ratio to compare all these nested models. A $P$ value of 0.2 was considered for inclusion of nonlinear and interaction terms in multivariable models.

To compare the models, Akaike information criterion (AIC) was used. Calibration of the models was graphically evaluated by creating model-based risk plots and was further assessed with the Greenwood-D'AgostinoNam test [17]. The discriminative performance of the fitted models was assessed by calculating the modified cstatistic by using the technique of inverse probability of censoring weighting (IPCW) for censored data [18].

To evaluate the implication of NT-proBNP on risk assessment, performance of the ACC/AHA and the ACC/ AHA + NT-proBNP models for 10-year HF prediction were compared. We assessed the performance of the two models by calculating the time-dependent sensitivity, specificity, positive and negative predicted values for survival data. To do this, risk cutoffs introduced by the ACC/AHA guideline for ASCVD (5\%, 7.5\%, and 20\%) were used [19]. We also calculated continuous and categorical NRIs. Reclassification tables were constructed to investigate the number of individuals with and without the HF event, reclassified to a higher or lower category of 10-year risk for HF. Risk categories were defined using the same cutoffs [low-risk $(<5 \%)$, borderline risk $(\geq 5 \%$ and $<7.5 \%)$, intermediate risk $(\geq 7.5 \%$ and $<20 \%)$, and high risk $(\geq 20 \%)$.

The original ACC/AHA model was developed for ASCVD risk calculation among asymptomatic individuals. Therefore, as a sensitivity analysis, the performance of the ACC/AHA model was also evaluated after addition of CHD history to the model. Furthermore, all analyses were once repeated in a sample with further exclusions for prevalent $\mathrm{CHD}$ and $\mathrm{AF}$ and use of lipid lowering medication based on the ACC/AHA guidelines.

All analyses were performed using $\mathrm{R}$ version 3.6.1 (Packages: mice, rms, survC1, timeROC, ggplot2).

\section{Results}

Mean (SD) age was 68.0 (7.78) years in men and 69.2 (8.58) years in women (Table 1). Mean BMI $\left(\mathrm{kg} / \mathrm{m}^{2}\right)$ was slightly higher in women [26.5 (3.27) in men versus 27.3
(4.39) in women]. Glucose and creatinine levels were higher in men [6.09 (1.70) $\mathrm{mmol} / \mathrm{l}$ in men and 5.87 (1.47) $\mathrm{mmol} / \mathrm{l}$ in women for glucose and 89.0 (18.2) $\mathrm{mmol} / \mathrm{l}$ in men and $70.8(13.5) \mathrm{mmol} / \mathrm{l}$ in women for creatinine]. However, total and HDL cholesterol levels were higher in women. Thirty percent of men and 35\% of women used antihypertensives while $14 \%$ and $12 \%$ took lipid lowering medications, respectively. More men (13.8\%) had a history of CHD than women (3.3\%). Likewise, more men had diabetes $(14.7 \%$ compared to $11.6 \%$ in women). Median NT-proBNP levels were higher in women [median (IQR): 8.19 (13.4) in men and 10.8 (13.2) in women]. Data on covariates were missing for less than $5 \%$ in men and women.

During a median follow-up of 13 years, 429 and 489 incident cases of HF were identified in men and women, respectively (incident rate: 14.5 per 1000 person-years in men and 11.4 per 1000 person-years in women). Supplementary Table 1 (Additional file 1) details the multivariable-adjusted hazard ratios (HRs) and 95\% confidence intervals (95\% CIs) for 10-year incident $\mathrm{HF}$ for the ACC/AHA, the ARIC, the Health $\mathrm{ABC}$ and the ACC/AHA + NT-proBNP models in men and women.

Comparing the models, the Health $\mathrm{ABC}$ model had the lowest AIC in men and women (5651.2 and 6656.2, respectively) with 11 degrees of freedom (see Supplementary Table 2, Additional file 1). The overall fit of the ARIC model was 5953.2 in men 6908.0 in women with 9 degrees of freedom. The AIC of the ACC/AHA model was 6213.4 in men and 7503.2 in women. The AIC of the ACC/AHA model improved substantially $(P$ for the log-likelihood ratio test $<0.001)$ after adding NTproBNP (5970.9 in men and 7179.4 in women). Calibration plots of observed and predicted risks were reasonable (see Supplementary Figure 1, Additional file 1). The Greenwood-D'Agostino-Nam test also indicated that all models were well-calibrated (All $P>0.20$ ).

Figure 2 shows the discriminative performance of each model in men and women. The ARIC model had the highest discriminative ability in men and women [c-statistic (95\% CI): 0.80 (0.78 to 0.83 ) and 0.80 (0.78 to 0.83 ), respectively]. The c-statistic for the ACC/AHA model was 0.76 (0.74 to 0.78$)$ in men and 0.77 (0.75 to 0.80$)$ in women. By adding NT-proBNP to the ACC/AHA model, the c-statistic increased to 0.80 (0.78 to 0.83 ) in men and 0.81 (0.79 to 0.84 ) in women.

Using cutoffs introduced by the recent ACC/AHA guidelines, the ACC/AHA model categorized $0.04 \%$ of men as low risk, $1.5 \%$ as borderline, $27.6 \%$ as intermediate, and $70.9 \%$ as high risk (Fig. 3). Among women, the ACC/AHA model allocated 7\% as low risk, $14.4 \%$ as borderline, $38.2 \%$ as intermediate, and $40.4 \%$ as high risk. Continuous NRI $(95 \% \mathrm{CI})$ after adding NT-proBNP to the ACC/AHA model was 0.08 ( -0.08 to 0.16$)$ in men 
Table 1 Characteristics of the study population

\begin{tabular}{|c|c|c|c|}
\hline Clinical features & Men $(N=2743)$ & Women $(N=3646)$ & $P$ value* \\
\hline Age, years & $68.0(7.78)$ & $69.2(8.58)$ & $<0.001$ \\
\hline $\mathrm{BMl}, \mathrm{kg} / \mathrm{m}^{2}$ & $26.5(3.27)$ & $27.3(4.39)$ & $<0.001$ \\
\hline Systolic blood pressure, mmHg & $142(20.8)$ & $143(21.5)$ & 0.350 \\
\hline Hear rate, bpm & $69.4(11.9)$ & $71.7(10.9)$ & 0.032 \\
\hline Total cholesterol, mmol/l & $5.54(0.95)$ & $6.01(0.95)$ & $<0.001$ \\
\hline $\mathrm{HDL}, \mathrm{mmol} / \mathrm{l}$ & $1.24(0.32)$ & $1.50(0.40)$ & $<0.001$ \\
\hline Antihypertensive use, N (\%) & $856(32.7)$ & $1220(35.3)$ & $<0.001$ \\
\hline Lipid lowering medication, N (\%) & $364(13.8)$ & $420(12.0)$ & $<0.001$ \\
\hline Creatinine, $\mathrm{mmol} / \mathrm{I}^{\dagger}$ & $89.0(18.2)$ & $70.8(13.5)$ & $<0.001$ \\
\hline Glucose, mmol/l & $6.09(1.70)$ & $5.87(1.47)$ & $<0.001$ \\
\hline LVH, N (\%) & $176(7.30)$ & $119(3.80)$ & 0.034 \\
\hline NT-proBNP, pmol// ${ }^{\dagger}$ & $8.19(13.4)$ & $10.8(13.2)$ & $<0.001$ \\
\hline Prevalent CHD, N (\%) & $370(13.8)$ & $118(3.30)$ & $<0.001$ \\
\hline Prevalent diabetes, N (\%) & $403(14.7)$ & $423(11.6)$ & 0.009 \\
\hline Smoking, N (\%) & & & $<0.001$ \\
\hline Current & $652(25.3)$ & $614(17.2)$ & - \\
\hline Past & $1604(62.2)$ & $1315(36.8)$ & - \\
\hline Never & $322(12.5)$ & $1648(46.1)$ & - \\
\hline
\end{tabular}

Data are mean (standard deviation (SD)) for continuous variables, ${ }^{\dagger}$ median (interquartile range (IQR)) for skewed variables, and number (percentage) for categorical variables from the original data

Proportion of missing: Among men: SBP: $0.18 \%$, heart rate: $0.55 \%$, total cholesterol, BMI and glucose: each $0.9 \%$, HDL: $1.7 \%$, creatinine: $1.6 \%$, NT-proBNP: $1.6 \%$, antihypertensive use: $2 \%$, smoking: $2.7 \%$, LVH: $2.9 \%$

Among women: SBP: $0.86 \%$, heart rate: $1.43 \%$, total cholesterol, glucose: $1.6 \%$, antihypertensive use: $1.8 \%$, smoking: $1.9 \%$, BMl: $2.1 \%$, creatinine: $1.8 \%$, NT-proBNP: $2 \%, \mathrm{HDL}: 2.6 \%$, LVH: $2.6 \%$

$B M I$ body mass index, CHD coronary heart disease, $H D L$ high-density lipoprotein, $L V H$ left ventricular hypertrophy

* $P$ value for differences in characteristics between men and women

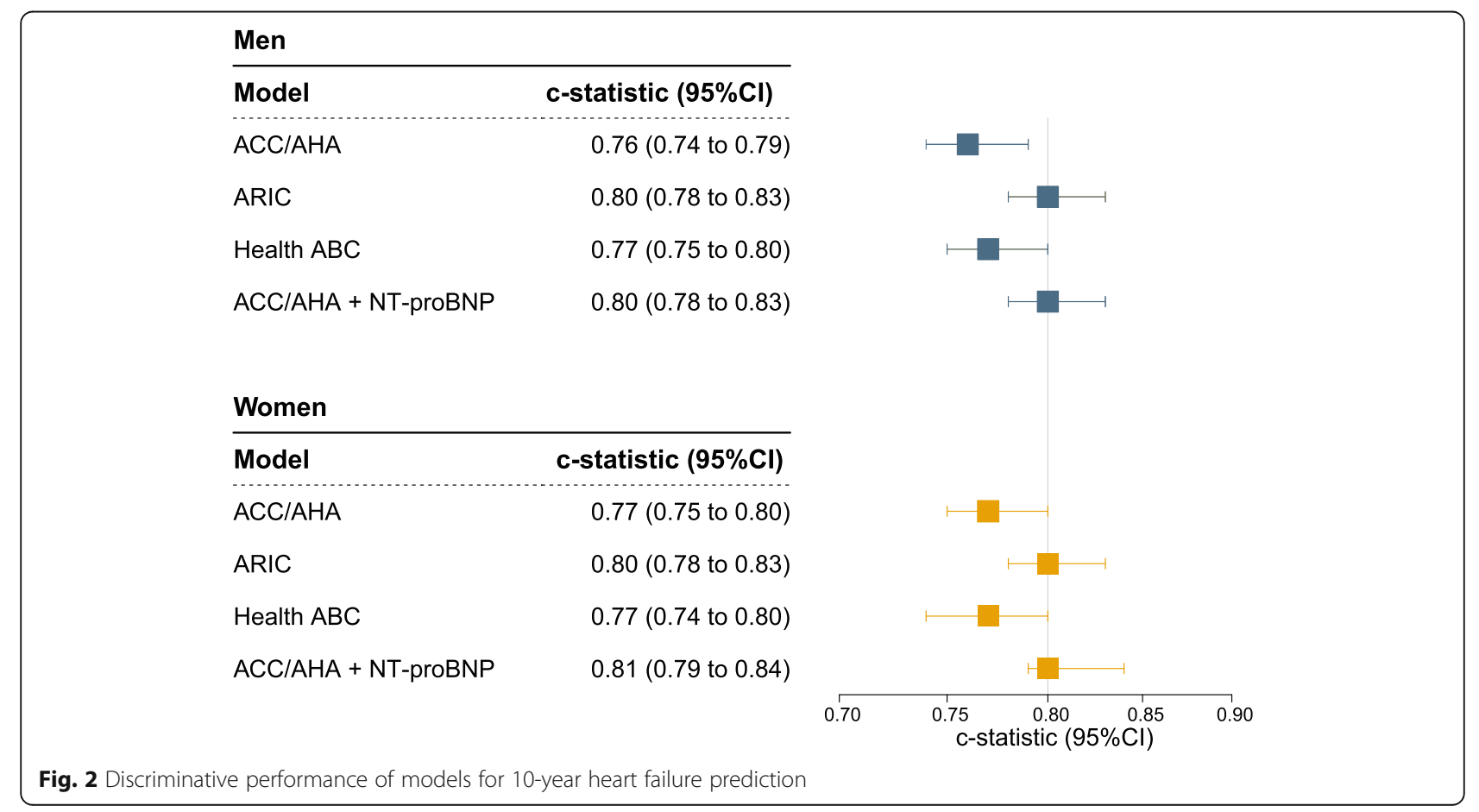




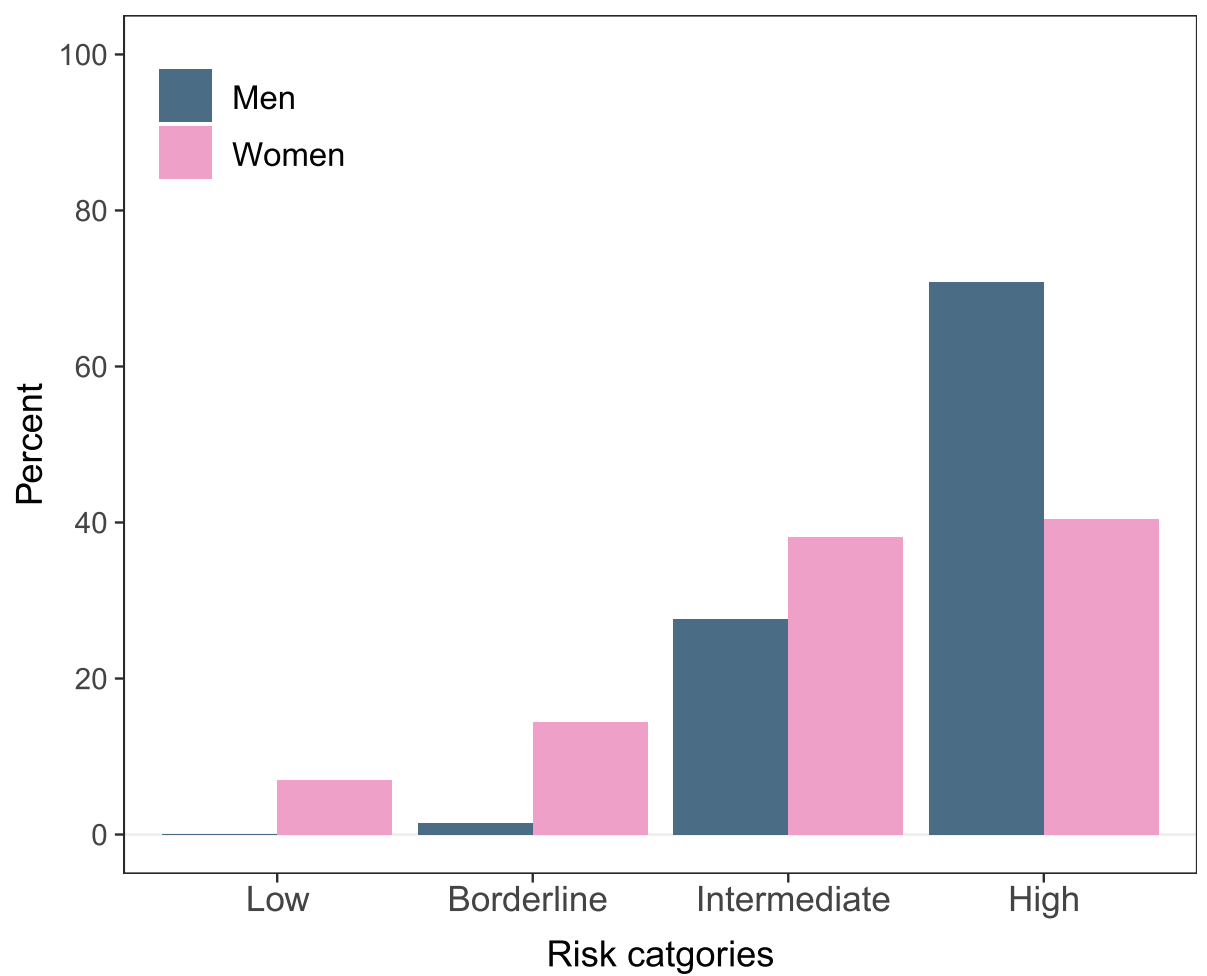

Fig. 3 Observed risk categories based on the ACC/AHA model in men and women. Risk categories are low-risk $(<5 \%)$, borderline risk $(\geq 5 \%$ and $<7.5 \%$ ), intermediate risk ( $\geq 7.5 \%$ and $<20 \%$ ), and high risk $(\geq 20 \%)$ ]

and $0.12(0.02$ to 0.22$)$ in women. As for categorical NRI, event NRI $(95 \%$ CI) was $-23.8 \%$ ( $-28.4 \%$ to $19.2 \%)$ and non-event NRI (95\% CI) was $57.9 \%$ (54.8\% to $61.0 \%)$ for men. Among women, event and non-event NRI $(95 \%$ CI) were $-27.6 \%(-30.7 \%$ to $-24.5 \%)$ and $52.8 \%$ (50.3\% to $55.5 \%$ ), respectively (see Supplementary Table 3, Additional file 1). Reclassification of individuals with and without the HF event to higher or lower risk categories is depicted in (see Supplementary Figure 2, Additional file 1).

Overall the sensitivity of the ACC/AHA + NT-proBNP model was higher using different cutoffs in men and women. Specificity and predictive discrimination values were similar for both models at the 5 and $7.5 \%$ risk thresholds (Table 2). As expected, the sensitivity declined and the specificity increased for both models when risk threshold increased from 5 to $7.5 \%$ and to $20 \%$. Using a cutoff of $20 \%$, the ACC/AHA model correctly classified $9 \%$ of men and women who developed HF during follow-up at high risk (sensitivity). Also, 99\% of men and women who remained event free during follow-up were correctly classified at low risk (specificity) by the ACC/AHA model. But, for the ACC/AHA + NT-proBNP model, the sensitivity and specificity were $16 \%$ and $99 \%$ in men, and $21 \%$ and $99 \%$ in women. From men and women categorized as $\geq 20 \%$ risk by the ACC/ AHA model $88 \%$ and 57\% developed HF during follow- up (positive predicted value), whereas from those categorized at low-risk group $89 \%$ of men and $92 \%$ of women remained event free during the follow-up (negative predicted value). For the ACC/AHA + NT-proBNP model, positive and negative predicted values were $84 \%$ and $90 \%$ in men, respectively. In women, the ACC/AHA + NT-proBNP model, positive and negative predicted values were $69 \%$ and 93\%, respectively. Results for the analyses using the thresholds of $5 \%, 7.5 \%$, and $20 \% 10$ year HF risk are shown in Table 2.

In sensitivity analyses, prevalent $\mathrm{CHD}$ was added to the ACC/AHA and the ACC/AHA + NT-proBNP models. We also repeated the analyses excluding participants with AF and prevalent $\mathrm{CHD}$ and those using lipid lowering medication according to the ACC/AHA guidelines. The performance of the models did not change substantially (data not shown).

\section{Discussion}

A simple model based on traditional cardiovascular risk factors included in the ACC/AHA model showed a reasonable performance in predicting 10-year HF among men and women from the population-based Rotterdam Study. The performance of the model based on ACC/ AHA risk factors for HF prediction was comparable to the models based on risk factors included in the ARIC and Health ABC HF models. Adding NT-proBNP to the 
Table 2 Comparison of the performance of the ACC/AHA model and ACC/AHA model with addition of NT-proBNP

\begin{tabular}{|c|c|c|c|}
\hline & \multicolumn{3}{|l|}{ Risk thresholds } \\
\hline & $5 \%$ & $7.5 \%$ & $20 \%$ \\
\hline \multicolumn{4}{|l|}{ Men } \\
\hline \multicolumn{4}{|l|}{ Sensitivity (95\% Cl) } \\
\hline $\mathrm{ACC} / \mathrm{AHA}$ & $80 \%(78 \%$ to $82 \%)$ & $50 \%(47 \%$ to $53 \%)$ & $9 \%(8 \%$ to $11 \%)$ \\
\hline ACC/AHA + NT-proBNP & $83 \%(81 \%$ to $85 \%)$ & $58 \%(55 \%$ to $61 \%)$ & $16 \%(14 \%$ to $18 \%)$ \\
\hline \multicolumn{4}{|l|}{ Specificity (95\% Cl) } \\
\hline $\mathrm{ACC} / \mathrm{AHA}$ & $70 \%(69 \%$ to $71 \%)$ & $90 \%(89 \%$ to $91 \%)$ & $99 \%(99 \%$ to $100 \%)$ \\
\hline ACC/AHA + NT-proBNP & $72 \%(71 \%$ to $73 \%)$ & $90 \%(89 \%$ to $91 \%)$ & $99 \%(99 \%$ to $100 \%)$ \\
\hline \multicolumn{4}{|c|}{ Positive predicted value (95\% Cl) } \\
\hline ACC/AHA & $27 \%$ (25\% to $28 \%)$ & $40 \%(37 \%$ to $43 \%)$ & $88 \%(80 \%$ to $96 \%)$ \\
\hline ACC/AHA + NT-proBNP & $29 \%(27 \%$ to $30 \%)$ & $44 \%$ (41\% to $46 \%)$ & $84 \%$ (79\% to $90 \%)$ \\
\hline \multicolumn{4}{|c|}{ Negative predicted value (95\% Cl) } \\
\hline $\mathrm{ACC} / \mathrm{AHA}$ & $96 \%(96 \%$ to $97 \%)$ & $93 \%(92 \%$ to $93 \%)$ & $89 \%$ (87\% to $89 \%)$ \\
\hline ACC/AHA + NT-proBNP & $97 \%$ (96\% to $97 \%)$ & $94 \%$ (93\% to $95 \%)$ & $90 \%(89 \%$ to $90 \%)$ \\
\hline \multicolumn{4}{|l|}{ Women } \\
\hline \multicolumn{4}{|l|}{ Sensitivity $(95 \% \mathrm{Cl})$} \\
\hline ACC/AHA & $81 \%(79 \%$ to $83 \%)$ & $52 \%(49 \%$ to $55 \%)$ & $9 \%(8 \%$ to $12 \%)$ \\
\hline ACC/AHA + NT-proBNP & $85 \%(83 \%$ to $87 \%)$ & $63 \%(60 \%$ to $66 \%)$ & $21 \%(18 \%$ to $23 \%)$ \\
\hline \multicolumn{4}{|l|}{ Specificity (95\% Cl) } \\
\hline $\mathrm{ACC} / \mathrm{AHA}$ & $67 \%(66 \%$ to $78 \%)$ & $89 \%(88 \%$ to $90 \%)$ & $99 \%(99 \%$ to $100 \%)$ \\
\hline ACC/AHA + NT-proBNP & $69 \%(68 \%$ to $70 \%)$ & $87 \%(86 \%$ to $88 \%)$ & $99 \%(99 \%$ to $100 \%)$ \\
\hline \multicolumn{4}{|c|}{ Positive predicted value (95\% Cl) } \\
\hline $\mathrm{ACC} / \mathrm{AHA}$ & $19 \%(18 \%$ to $20 \%)$ & $31 \%(29 \%$ to $33 \%)$ & $57 \%$ (48\% to $67 \%)$ \\
\hline ACC/AHA + NT-proBNP & $21 \%(20 \%$ to $22 \%)$ & $33 \%(31 \%$ to $35 \%)$ & $69 \%$ (64\% to $74 \%)$ \\
\hline \multicolumn{4}{|c|}{ Negative predicted value $(95 \% \mathrm{Cl})$} \\
\hline ACC/AHA & $97 \%$ (97\% to $98 \%)$ & $95 \%(95 \%$ to $96 \%)$ & $92 \%(91 \%$ to $93 \%)$ \\
\hline ACC/AHA + NT-proBNP & $98 \%$ (98\% to $99 \%)$ & $96 \%(95 \%$ to $96 \%)$ & $93 \%(92 \%$ to $93 \%)$ \\
\hline
\end{tabular}

ACC/AHA model modestly improved model performance but did not lead to relevant clinical improvement in risk reclassification.

Compared to $\mathrm{CHD}$ and stroke, prediction of incident HF remains a challenge $[5,6]$. In spite of the large number of risk prediction models developed for incident HF, there have been no recommendations for routine clinical use of any of the models in the existing guidelines [5]. This is while, preventive interventions significantly reduce the risk of incident HF [3]. In addition to generalizability issues and methodological heterogeneity, models specifically developed to predict HF are based on various markers which have higher technical demands and might not be available in all clinical settings $[5,8,9,20]$. HF can have ischemic or non-ischemic origins. Although $\mathrm{CHD}$ and hypertension are the leading causes of HF, a high proportion of this syndrome is attributed to other cardiometabolic risk factors [21]. Moreover, biomarkers have shown limited predictive capability for HF risk stratification and have not profited clinical decision making [22]. The ACC/AHA model for ASCVD risk assessment consists of the traditional cardiovascular risk factors that are also associated with HF [7]. In our analysis, the model based on traditional cardiovascular risk factors included in the ACC/AHA model had a performance almost similar to the Health ABC model and close to the ARIC model for HF risk assessment in general population. In a meta-analysis of HF prediction models, among the 53 potential predictors considered in 19 studies between 1990 and 2016, age, sex and systolic blood pressure were the most common selected predictors [6]. To note, the predictors in the ACC/AHA model were among the 10 most used predictors in these dedicated HF prediction models. They are also commonly used in predicting HF prognosis and other cardiovascular outcomes [23]. The acceptable performance of the model based on risk factors from the ACC/AHA algorithm for HF prediction in our study advocates implementing this model for primary $\mathrm{HF}$ 
prevention. Addition of NT-proBNP to the ACC/AHA model improved model performance in both sexes. There was overlap between men and women in the discrimination of both the ACC/AHA and the ACC/AHA + NTproBNP models. Nevertheless, the improvement in the cstatistic after addition of NT-proBNP was slightly greater among women. To note, levels of NT-proBNP/BNP have not shown to be different between men and women with acute or chronic HF [24]. Also, women have slightly lower NT-proBNP/BNP levels in clinical setting which has been attributed to higher prevalence of HF with preserved ejection fraction among women [25]. Thus, an overlap in the performance of the model by adding these biomarkers is not far from expectation.

Studies have shown mixed results regarding the contribution of NT-proBNP/BNP to improvement of CVD risk prediction in men and women [26]. NT-proBNP has displayed no or only modest impact in increasing the discriminative ability or risk classification of CVD risk prediction models in the general population [22, 25, 2729]. On the contrary, in high-risk individuals with previous history of CVD, higher prognostic ability has been reported [25]. It should be considered that a wide variety of cardiac and non-cardiac conditions are also associated with elevated serum levels of this biomarker [30]. Moreover, high levels of NT-proBNP are associated with creatinine level, sex, age, and inversely associated with BMI independent of ventricular function $[1,19$, 31]. This is probably why its discriminative ability for detection of left ventricular systolic dysfunction has been suboptimal, limiting its utility in mass screening [32].

Using different cutoffs, addition of NT-proBNP was accompanied by slight increases in the sensitivity and specificity of the models in both sexes. Only at the $20 \%$ cutoff, the difference in the sensitivity and specificity of the two models was more evident and NT-proBNP increased the NPV and PPV of the model more evidently. Also, continuous NRI in men was smaller than women. However, using the ACC/AHA risk cutoffs, NT-proBNP mainly correctly down-classified participants without the event in both sexes and did not show large improvement in reclassifying participants with the event. In line with our study, Willeit et al. showed a strong association between NT-proBNP and the composite outcome of stroke, CHD, and HF [28]. But the increase in the c-statistic of the model after adding NT-proBNP was modest. Interestingly, they also specified that NT-proBNP improved risk prediction by appropriately down classifying the clinical risk of those without the event. Moreover, they observed similar changes using cutoffs used by different guidelines [28].
NT-proBNP/BNP is an established diagnostic and prognostic biomarker in HF patients [31]. For prediction of incident HF alone, NT-proBNP/BNP has shown to improve model performance [8, 33, 34]. However, despite the association of increasing NT-proBNP/BNP levels with substantial risk of HF, it is not a costeffective screening tool to assess for preclinical heart failure or LV dysfunction, limiting its utility to highly selected populations [30]. In this regard, NT-proBNP testing has a clear and valuable role in the diagnosis of $\mathrm{CHF}$ in the emergency diagnosis of patients with dyspnea [35]. The strength of BNP is in its ability to rule out $\mathrm{CHF}$ in this setting. Likewise, the favorable clinical utility of adding NT-proBNP to the ACC/AHA model in risk reclassification was mainly limited to the non-events in our study. To add, BNP has shown a high NPV to rule out diastolic dysfunction or LVH [36, 37]. The ACC/ AHA + NT-proBNP model also showed a high NPV for HF in our study using different risk cutoffs but the differences were more evident among those at high risk, using a cutoff of $20 \%$ which again emphasizes that NTproBNP might be useful in prediction of HF only among high risk populations. Specifically, this utilization might be more towards ruling out HF rather than its rule-in ability [30].

Strengths of our study are use of a large sample size and detailed long follow-up data. Our HF event adjudication was robust and well-defined. Moreover, a large set of various and precisely measured variables were available for this study. There are also limitations. The Rotterdam Study population is mainly white and 45 years of age and older, compared with the ARIC and the PCE study populations. Mean age of the study population in the ARIC study [54.1(6.0) years] was younger than our total population [69.7 (8.27)] while mean age in the health ABC study [73.6 (2.9)] was somewhat closer to our study population, but with less variability. As the strongest predictor of HF, differences in age could explain to some extent the differences in the performance of the models. Hence, we refitted the models based on the variables used in the risk scores. Our study is an attempt for internal validation of the ACC/AHA risk score for prediction of incident HF which may have led to overestimation of its performance. To assess the transferability of predictive models, they need to be externally validated to make it possible for them to be used in clinical settings [5, 6]. Also, because of unavailability of albumin, we were not able to include it in the Health $A B C$ model. In addition, we did not have data on HF subtypes at the time of diagnosis. Inaccessibility of data on subtypes of HF is also a limitation of population-based cohort studies, like the ARIC and the health ABC studies. Moreover, our results might not be generalizable to younger individuals and other ethnicities. 


\section{Conclusion}

The model based on traditional risk factors included in the ACC/AHA model had an acceptable performance, comparable to more sophisticated models, for predicting 10-year HF among men and women from the general population. Our results therefore advocate use of this model for HF primary prevention. Addition of NTproBNP to the ACC/AHA model leads to modest improvement in model performance, in particular among women. However, the clinical relevance of adding this biomarker for correct risk reclassification is limited.

\section{Supplementary Information}

The online version contains supplementary material available at https://doi. org/10.1186/s12916-021-01916-7.

Additional file 1: Supplementary Table 1. Hazard ratios for incident $\mathrm{HF}$ in the ACC/AHA model, ARIC model, Health ABC model and ACC/ AHA + NT-proBNP model in men and women. Supplementary Table 2. Overall goodness-of-fit for the ACC/AHA model, ARIC model, Health ABC model and ACC + NT-proBNP model in men and women. Supplementary Table 3. Risk reclassification for the ACC/AHA model after adding NT-proBNP stratified by event status. Supplementary Table 4. Fine and Gray's subdistribution hazard ratios for incident HF and mortality in the ACC/AHA model, ARIC model, Health ABC model and ACC/AHA + NTproBNP model in men and women. Supplementary Figure 1. Calibration plots for the observed and predicted risk based on the ACC/AHA model, ARIC model, Health ABC model and ACC + NT-proBNP model in men and women. Supplementary Figure 2. Risk reclassification for the ACC/AHA model after adding NT-proBNP stratified by event status.

\section{Acknowledgements}

The authors are grateful to the study participants, the staff from the Rotterdam Study and the participating general practitioners and pharmacists. We also appreciatively thank Janine E. van der Toorn (Department of Epidemiology, Erasmus MC, University Medical Centre Rotterdam, Rotterdam, the Netherlands) for providing us with the figure layout for risk stratification.

\section{Authors' contributions \\ For this manuscript, Banafsheh Arshi has been involved in data curation, analysis, investigation, methodology, visualization, writing, and editing; Jan C. van den Berge and Bart van Dijk have been part of data curation, analysis, reviewing, and editing; and Jaap W. Deckers and M. Arfan Ikram have contributed to the data curation, methodology, writing, and reviewing. Maryam Kavousi has been part of the conceptualization, methodology, administration, supervision, writing, reviewing, and editing. All authors have read and approved the manuscript.}

\section{Funding}

The Rotterdam Study is funded by Erasmus Medical Center and Erasmus University, Rotterdam, Netherlands Organization for the Health Research and Development (ZonMw), the Research Institute for Diseases in the Elderly (RIDE), the Ministry of Education, Culture and Science, the Ministry for Health, Welfare and Sports, the European Commission (DG XII), and the Municipality of Rotterdam.

\section{Availability of data and materials}

The analyzed datasets during the current study are not publicly available due to legal and ethical restraints. Sharing of individual participant data was not included in the informed consent of the study, and there is potential risk of revealing participants' identities as it is not possible to completely anonymize the data. However, data are available from the corresponding author on reasonable request.

\section{Ethics approval and consent to participate}

The Rotterdam Study has been approved by the Medical Ethics Committee of the Erasmus MC (registration number MEC 02.1015) and the Dutch Ministry of Health, Welfare and Sport (Population Screening Act WBO, license number 1071272-159521-PG). In addition, the Rotterdam Study has been entered into the Netherlands National Trial Register (NTR; www.trialregister.nl) and the WHO International Clinical Trials Registry Platform (ICTRP; www.who. int/ictrp/network/primary/en/) under shared catalog number NTR6831. All participants provided written informed consent for participation and data collection from general practitioners and pharmacies.

\section{Consent for publication}

Not applicable.

\section{Competing interests}

The authors declare that they have no competing interests.

\section{Author details}

${ }^{1}$ Department of Epidemiology, Erasmus MC - University Medical Center Rotterdam, Rotterdam, The Netherlands. 'Department of Cardiology, Erasmus MC - University Medical Center Rotterdam, Rotterdam, The Netherlands.

Received: 24 August 2020 Accepted: 15 January 2021

Published online: 16 February 2021

\section{References}

1. Ponikowski P, Voors AA, Anker SD, Bueno H, Cleland JGF, Coats AJS, Falk V, González-Juanatey JR, Harjola VP, Jankowska EA. 2016 ESC Guidelines for the diagnosis and treatment of acute and chronic heart failure: the Task Force for the diagnosis and treatment of acute and chronic heart failure of the European Society of Cardiology (ESC). Developed with the special contribution of the Heart Failure Association (HFA) of the ESC. Eur J Heart Fail. 2016;18(8):891-975.

2. Yancy CW, Jessup M, Bozkurt B, Butler J, Casey DE, Drazner MH, Fonarow GC, Geraci SA, Horwich T, Januzzi JL. 2013 ACCF/AHA guideline for the management of heart failure: a report of the American College of Cardiology Foundation/American Heart Association Task Force on Practice Guidelines. J Am Coll Cardiol. 2013;62(16):e147-239.

3. Ponikowski P, Anker SD, AlHabib KF, Cowie MR, Force TL, Hu S, Jaarsma T, Krum H, Rastogi V, Rohde LE. Heart failure: preventing disease and death worldwide. ESC Heart Fail. 2014;1(1):4-25.

4. Butler J. Primary prevention of heart failure. ISRN Cardiol. 2012;2012:982417. https://doi.org/10.5402/2012/982417. Epub 2012 Aug 16. PMID: 22957272; PMCID: PMC3431085.

5. Echouffo-Tcheugui JB, Greene SJ, Papadimitriou L, Zannad F, Yancy CW, Gheorghiade M, Butler J. Population risk prediction models for incident heart failure: a systematic review. Circ Heart Fail. 2015;8(3):438-47.

6. Sahle BW, Owen AJ, Chin KL, Reid CM. Risk prediction models for incident heart failure: a systematic review of methodology and model performance. J Card Fail. 2017:23(9):680-7.

7. Goff DC, Lloyd-Jones DM, Bennett G, Coady S, D'Agostino RB, Gibbons R, Greenland P, Lackland DT, Levy D, O'donnell CJ. 2013 ACC/AHA guideline on the assessment of cardiovascular risk: a report of the American College of Cardiology/American Heart Association Task Force on Practice Guidelines. J Am Coll Cardiol. 2014;63(25 part B):2935-59.

8. Agarwal SK, Chambless LE, Ballantyne CM, Astor B, Bertoni AG, Chang PP, Folsom AR, He M, Hoogeveen $\mathrm{RC}, \mathrm{Ni} \mathrm{H}$. Prediction of incident heart failure in general practice: the Atherosclerosis Risk in Communities (ARIC) Study. Circ Heart Fail. 2012;5(4):422-9.

9. Butler J, Kalogeropoulos A, Georgiopoulou V, Belue R, Rodondi N, Garcia M, Bauer DC, Satterfield S, Smith AL, Vaccarino V. Incident heart failure prediction in the elderly: the health $A B C$ heart failure score. Circ Heart Fail. 2008;1(2):125-33.

10. Ikram MA, Brusselle G, Ghanbari M, Goedegebure A, Ikram MK, Kavousi M, Kieboom BCT, Klaver CCW, de Knegt RJ, Luik Al. Objectives, design and main findings until 2020 from the Rotterdam Study. Eur J Epidemiol. 2020; 35(5):483-517.

11. Leening MJG, Kavousi M, Heeringa J, van Rooij FJA, Verkroost-van Heemst J, Deckers JW, Mattace-Raso FUS, Ziere G, Hofman A, Stricker BHC. Methods of 
data collection and definitions of cardiac outcomes in the Rotterdam Study. Eur J Epidemiol. 2012;27(3):173-85.

12. Yeo K-TJ WAHB, Apple FS, Kroll MH, Christenson RH, Lewandrowski KB, Sedor FA, Butch AW. Multicenter evaluation of the Roche NT-proBNP assay and comparison to the Biosite Triage BNP assay. Clin Chim Acta. 2003; 338(1-2):107-15.

13. De Bruyne MC, Kors JA, Hoes AW, Kruijssen DAC, Deckers JW, Grosfeld M, van Herpen G, Grobbee DE, Van Bemmel JH. Diagnostic interpretation of electrocardiograms in population-based research: computer program research physicians, or cardiologists? J Clin Epidemiol. 1997;50(8):947-52

14. Bleumink GS, Knetsch AM, Sturkenboom MCJM, Straus SMJM, Hofman A, Deckers JW, Witteman JCM, Stricker BHC. Quantifying the heart failure epidemic: prevalence, incidence rate, lifetime risk and prognosis of heart failure: the Rotterdam Study. Eur Heart J. 2004;25(18):1614-9.

15. Swedberg K, Cleland J, Dargie H, Drexler H, Follath F, Komajda M, Tavazzi L, Smiseth OA, Gavazzi A, Haverich A. Guidelines for the diagnosis and treatment of chronic heart failure: executive summary (update 2005) the Task Force for the Diagnosis and Treatment of Chronic Heart Failure of the European Society of Cardiology. Eur Heart J. 2005:26(11):1115-40.

16. van Buuren S, Groothuis-Oudshoorn K. MICE: multivariate imputation by chained equations in R. J Stat Softw. 2011;1(3):26.

17. Demler OV, Paynter NP, Cook NR. Tests of calibration and goodness-of-fit in the survival setting. Stat Med. 2015;34(10):1659-80.

18. Uno H, Cai T, Pencina MJ, D'Agostino RB, Wei L-J. On the C-statistics for evaluating overall adequacy of risk prediction procedures with censored survival data. Stat Med. 2011;30(10):1105-17.

19. Yancy CW, Jessup M, Bozkurt B, Butler J, Casey DE, Colvin MM, Drazner MH, Filippatos GS, Fonarow GC, Givertz MM. 2017 ACC/AHA/HFSA focused update of the 2013 ACCF/AHA guideline for the management of heart failure: a report of the American College of Cardiology/American Heart Association Task Force on Clinical Practice Guidelines and the Heart Failure Society of America. J Am Coll Cardiol. 2017;70(6):776-803.

20. Velagaleti RS, Gona P, Larson MG, Wang TJ, Levy D, Benjamin EJ, Selhub J, Jacques PF, Meigs JB, Tofler GH. Multimarker approach for the prediction of heart failure incidence in the community. Circulation. 2010;122(17):1700-6.

21. Hippisley-Cox J, Coupland C, Vinogradova Y, Robson J, May M, Brindle P. Derivation and validation of QRISK, a new cardiovascular disease risk score for the United Kingdom: prospective open cohort study. BMJ. 2007; 335(7611):136

22. Ioannidis JPA, Tzoulaki I. Minimal and null predictive effects for the most popular blood biomarkers of cardiovascular disease. Circ Res. 2012;110(5): 658-62.

23. Damen JAAG, Hooft L, Schuit E, Debray TPA, Collins GS, Tzoulaki I, Lassale CM, Siontis GCM, Chiocchia V, Roberts C. Prediction models for cardiovascular disease risk in the general population: systematic review. BMJ. 2016;353:i2416.

24. Motiwala SR, Sarma A, Januzzi JL, O'Donoghue ML. Biomarkers in ACS and heart failure: should men and women be interpreted differently? Clin Chem. 2014;60(1):35-43.

25. Manson JE, Bassuk SS. Biomarkers of cardiovascular disease risk in women. Metabolism. 2015;64(3):S33-9.

26. Paynter NP, Everett BM, Cook NR. Cardiovascular disease risk prediction in women: is there a role for novel biomarkers? Clin Chem. 2014;60(1):88-97.

27. Rutten JHW, Mattace-Raso FUS, Steyerberg EW, Lindemans J, Hofman A, Wieberdink RG, Breteler MMB, Witteman JCM, van den Meiracker AH. Amino-terminal pro-B-type natriuretic peptide improves cardiovascular and cerebrovascular risk prediction in the population: the Rotterdam study. Hypertension. 2010;55(3):785-91.

28. Willeit P, Kaptoge S, Welsh P, Butterworth AS, Chowdhury R, Spackman SA Pennells L, Gao P, Burgess S, Freitag DF. Natriuretic peptides and integrated risk assessment for cardiovascular disease: an individual-participant-data meta-analysis. Lancet Diab Endocrinol. 2016;4(10):840-9.

29. Yan I, Börschel CS, Neumann JT, Sprünker NA, Makarova N, Kontto J, Kuulasmaa K, Salomaa V, Magnussen C, lacoviello L. High-sensitivity cardiac troponin I levels and prediction of heart failure: results from the BiomarCaRE Consortium. JACC: Heart Fail. 2020;8(5):401-11.

30. Burke MA, Cotts WG. Interpretation of B-type natriuretic peptide in cardiac disease and other comorbid conditions. Heart Fail Rev. 2007:12(1):23-36.

31. Böhm M, Voors AA, Ketelslegers J-M, Schirmer SH, Turgonyi E, Bramlage P, Zannad F. Biomarkers: optimizing treatment guidance in heart failure. Clin Res Cardiol. 2011;100(11):973.
32. Vasan RS, Benjamin EJ, Larson MG, Leip EP, Wang TJ, Wilson PWF, Levy D. Plasma natriuretic peptides for community screening for left ventricular hypertrophy and systolic dysfunction: the Framingham heart study. JAMA. 2002;288(10):1252-9.

33. Smith JG, Newton-Cheh C, Almgren P, Struck J, Morgenthaler NG, Bergmann A, Platonov PG, Hedblad B, Engström G, Wang TJ. Assessment of conventional cardiovascular risk factors and multiple biomarkers for the prediction of incident heart failure and atrial fibrillation. J Am Coll Cardiol. 2010;56(21):1712-9.

34. Kalogeropoulos AP, Georgiopoulou W, deFilippi CR, Gottdiener JS, Butler J: Echocardiography, natriuretic peptides, and risk for incident heart failure in older adults: the Cardiovascular Health Study. JACC Cardiovasc Imaging 2012, 5(2):131-140.

35. Latour-Pérez J, Coves-Orts FJ, Abad-Terrado C, Abraira V, Zamora J. Accuracy of B-type natriuretic peptide levels in the diagnosis of left ventricular dysfunction and heart failure: a systematic review. Eur J Heart Fail. 2006;8(4): 390-9.

36. Conen D, Zeller A, Pfisterer M, Martina B. Usefulness of B-type natriuretic peptide and $\mathrm{C}$-reactive protein in predicting the presence or absence of left ventricular hypertrophy in patients with systemic hypertension. Am J Cardiol. 2006;97(2):249-52.

37. Arteaga E, Araujo AQ, Buck P, lanni BM, Rabello R, Mady C. Plasma aminoterminal pro-B-type natriuretic peptide quantification in hypertrophic cardiomyopathy. Am Heart J. 2005;150(6):1228-32.

\section{Publisher's Note}

Springer Nature remains neutral with regard to jurisdictional claims in published maps and institutional affiliations.

\section{Ready to submit your research? Choose BMC and benefit from:}

- fast, convenient online submission

- thorough peer review by experienced researchers in your field

- rapid publication on acceptance

- support for research data, including large and complex data types

- gold Open Access which fosters wider collaboration and increased citations

- maximum visibility for your research: over $100 \mathrm{M}$ website views per year

At $\mathrm{BMC}$, research is always in progress.

Learn more biomedcentral.com/submissions 